\title{
Measuring the quality of allied health services in Australia: is it a case of "the more we learn, the less we know?"
}

This article was published in the following Dove Press journal:

Journal of Healthcare Leadership

26 July 2012

Number of times this article has been viewed

\author{
Karen Grimmer-Somers \\ Steve Milanese \\ Saravana Kumar \\ International Centre for Allied Health \\ Evidence (iCAHE), University of South \\ Australia, North Terrace, Adelaide, \\ Australia
}

Background: Sensitive and reliable measurement of allied health $(\mathrm{AH})$ service quality is in its infancy. This is largely related to the complexity of the AH discipline-mix, the services these disciplines provide, and the locations in which services are provided. AH is variably described, with up to 49 disciplines being listed in the literature. These disciplines often undertake a range of interlinked activities such as assessment and diagnosis, counseling, therapy and rehabilitation, manufacture, education, and service organization. AH disciplines work in a range of roles in a range of public and private sector organizations, and often consult with their patients/ clients a number of times for the management of one condition. They operate under a variety of funding models, and often within service delivery constraints. This evidence-informed analytical review outlines factors which should be considered by allied health leaders, reflecting clinicians, policy-makers, managers, and academics, in regards to making an informed choice of sensitive and reliable measures of AH service quality. Strong, visionary, and collaborative leadership is required to ensure that allied health activities and outcomes are measured and reported effectively and efficiently.

Keywords: allied health (AH), sensitive, reliable measures, health service quality

\section{Introduction}

Measuring and monitoring aspects of the services provided by healthcare practitioners, either as individuals or as organizations, is the most common method for estimating the quality of care that is being provided. ${ }^{1}$ This requires the regular collection, analysis, and reporting of data items which sensitively, specifically, and reliably reflect the nature of the service being provided, its purpose, its customers, and outcomes. There is increasing pressure on allied health $(\mathrm{AH})$ leaders in public and private sectors to demonstrate service quality. However objective data to underpin reporting of any quality element is often not available.

There is no agreed approach to measuring or monitoring AH service quality. This is most likely because of the range and complexity of services offered by the disciplines listed under the AH umbrella. ${ }^{2}$ These disciplines have different purposes and ways of operating, different customers, stakeholders, outcomes, and quality measures. This paper presents an evidence-informed analytical review that raises issues which may assist $\mathrm{AH}$ leaders in considering the many issues relevant to measuring and monitoring AH service quality. Fifteen factors are considered within the context of the Australian healthcare system, relative to AH disciplines, organizations (operations) in which $\mathrm{AH}$ services are provided, and patients/customers of AH services. Figure 1 provides an overview of the factors discussed in this paper. This figure highlights that some factors 


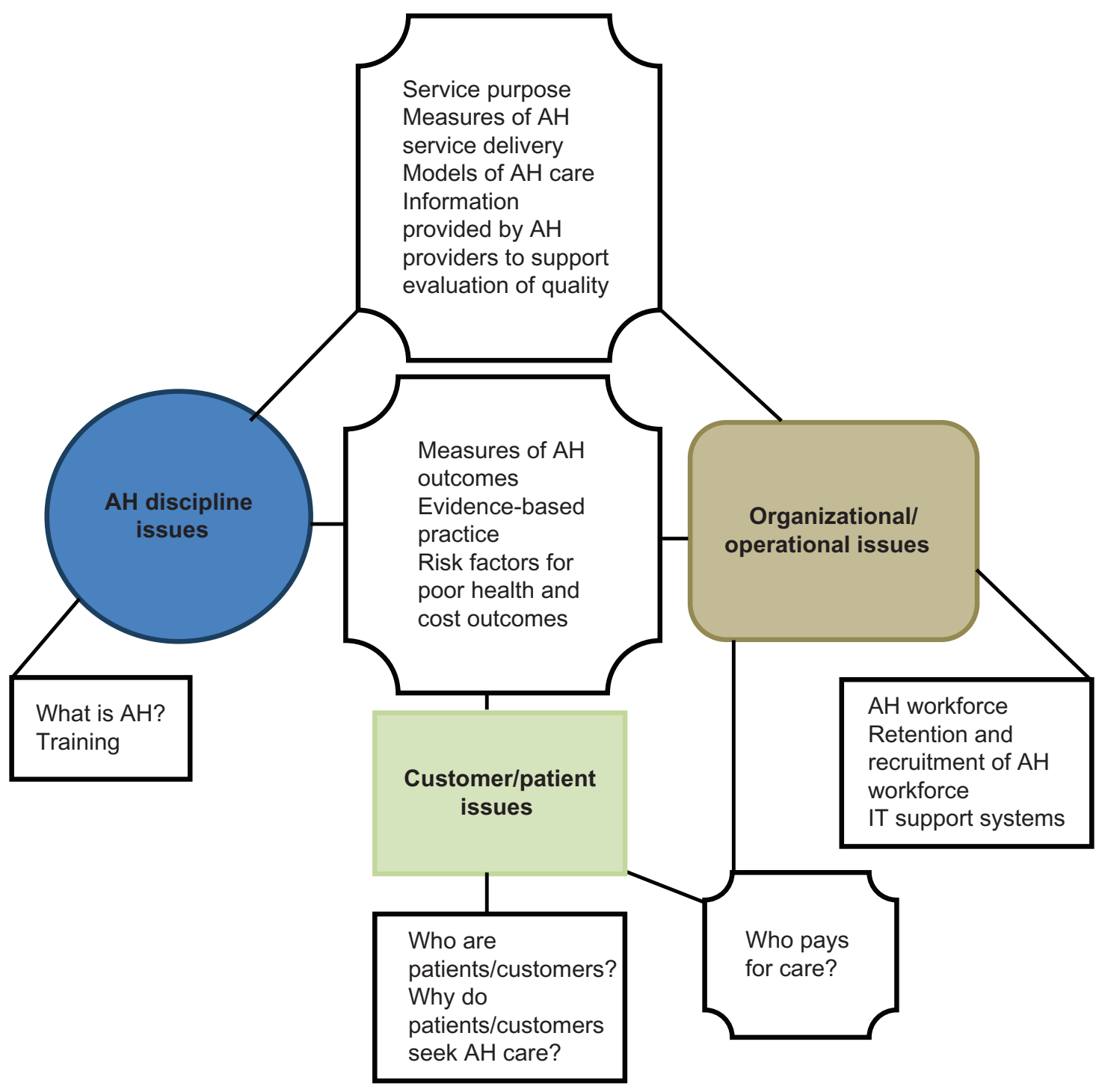

Figure I Factors of allied health services in Australia.

Abbreviations: $\mathrm{AH}$, allied health; IT, information technology.

are unique to one area, while others are shared. This figure also highlights the need for individual as well as collaborative leadership to address the multiple issues which impact the measurement of AH quality.

\section{What is $\mathrm{AH}$ ?}

AH is an "umbrella" term broadly encompassing health disciplines other than medicine and nursing. Although many authors have attempted to define $\mathrm{AH},{ }^{3,4}$ there remains a lack of an internationally recognized definition. The most common approach is simply to list disciplines which are “in," or "out." List membership varies between institutions, organizations, and countries, ${ }^{2,5-9}$ with the most extensive list of AH disciplines $(\mathrm{N}=49)$ provided in 2001 by Services for Australian Rural and Remote Allied Health. ${ }^{4}$ The lack of a definitive AH definition has supported seemingly ad hoc inclusions/exclusions to lists of $\mathrm{AH}$ disciplines operating in Australian healthcare environments. This has precluded a comprehensive understanding of AH quality service issues. ${ }^{10}$ Commonly listed AH services include audiology, dietetics and nutrition, occupational therapy, orthotics and prosthetics, physiotherapy, podiatry, psychology, radiography, and speech pathology. Social work and pharmacy may or may not be included.

\section{AH workforce}

In the most recent Australian health workforce statistics, ${ }^{11}$ there were 57,019 medical practitioners, 65,284 AH professionals (not including pharmacists or complementary medicine practitioners), and 202,735 registered nurses. This suggests that 
in 2010, AH disciplines in Australia contributed approximately $20 \%$ of the mainstream health workforce.

\section{Who is a patient/customer?}

There are direct and indirect customers/stakeholders in $\mathrm{AH}$ services whose interests and inputs need to be considered when measuring service quality. Direct customers/stakeholders include the $\mathrm{AH}$ provider, patient, and payer (patient or an insurer [private or compensable]), while indirect customers/ stakeholders include employers, family, other healthcare practitioners involved in caring for the patient, registration boards, professional associations, training organizations, and the general public. Customers/stakeholders will potentially have different interests in service quality, and different perspectives on how it should be measured. ${ }^{12,13}$

\section{Service purpose}

The general aim of any AH discipline is to optimize functional capacity and quality of life throughout the lifespan, although AH services rarely impact directly on mortality. ${ }^{14-16}$ Turnbull et $\mathrm{al}^{2}$ presented a three-dimensional task-based approach to describe $\mathrm{AH}$ activities, based on Grimmer and Kumar's ${ }^{17} \mathrm{AH}$ task model. AH tasks can be broadly described as primary treatment, assessment, diagnosis, counseling, education, manufacture/prescription, and organization. One AH discipline may undertake a number of these tasks when managing a single patient, or alternatively one task may be shared with other $\mathrm{AH}$ disciplines, medical professionals, and/or nurses. Since the mid-1990s, multidisciplinary/ interdisciplinary healthcare, which integrates $\mathrm{AH}$, medicine and nursing care for holistic patient management has been promoted, ${ }^{18}$ although there are limited examples of how to operationalize this approach.

\section{Training}

$\mathrm{AH}$ is not static. Internationally, $\mathrm{AH}$ training programs continue to evolve and new (or extensions of existing) disciplines are emerging. In Australia, formal training provided at universities and vocational colleges is now the norm for many $\mathrm{AH}$ disciplines. An increasing number of $\mathrm{AH}$ disciplines now require registration to legally practice. Accredited training programs have the primary responsibility of ensuring that $\mathrm{AH}$ graduates are competent in all the core aspects of care expected of them under the relevant state or national registration requirements. The traditional Australian undergraduate $\mathrm{AH}$ training program model has been expanded to incorporate a graduate entry model, where graduates from other programs enrol into shorter, more intensive programs of AH training. While this approach has been studied in the training of medical graduates, ${ }^{19}$ there has been little evaluation of this approach for $\mathrm{AH}$, particularly in terms of graduate and employer satisfaction, competence, and longevity in the profession.

\section{Recruitment and retention of AH workforce}

Retention of $\mathrm{AH}$ practitioners in Australia remains a major service quality issue. Attrition has been attributed to various reasons such as family responsibilities, disillusionment, a desire for change, high stress levels, lack of management support, travel, and transference to postgraduate medical courses. ${ }^{10}$ Burnout of AH practitioners is a well- and longrecognized issue around the world. ${ }^{20-22}$ This may well result from a tension between the high demands of university courses and the nature of the $\mathrm{AH}$ tasks which newly graduated practitioners undertake in the "real" world. Most $\mathrm{AH}$ training programs require high tertiary entrance scores, however the nature of the work post-graduation has been recognized as less than satisfying for many graduates. ${ }^{21}$ In Australia, anecdotally, there is a flow of newly graduated $\mathrm{AH}$ practitioners to graduate-entry medicine programs. This is believed to reflect young people who failed to be accepted into medicine as their primary tertiary training choice after graduation (and who enrolled into an $\mathrm{AH}$ training program as a second option), or who became dissatisfied with their choice of $\mathrm{AH}$ profession while training, or in the first year or two post-graduation.

While in Australia, recommendations from taskforces in New South Wales ${ }^{23,26}$ Queensland, ${ }^{24}$ South Australia, ${ }^{25}$ and Western Australia ${ }^{26}$ have been made on how to improve retention amongst $\mathrm{AH}$ practitioners, they have generally been workplace-specific rather than professional-based..$^{10}$ Thus, there is a clear opportunity to understand AH service quality relative to the elements related to workplace retention and job satisfaction.

AH practice in Australia is rapidly evolving, described in terms of a skills escalator continuum. ${ }^{27}$ At the left end of the continuum are formally-trained $\mathrm{AH}$ assistants. ${ }^{28}$ Their role is promoted as "unloading" AH practitioners of routine duties such as equipment cleaning and maintenance, exercise supervision, patient monitoring, and other simple tasks so that $\mathrm{AH}$ clinicians can work on more complex duties. ${ }^{28}$ At the right end of the continuum are extended scope $\mathrm{AH}$ practitioners, whose roles are currently being explored in public hospital emergency departments and outpatient clinics. Appropriately skilled AH practitioners undertake 
"extended scope" activities such as prescription of medications, ordering and interpreting diagnostic tests, giving injections, and undertaking minor surgery. These activities are promoted as a way to enhance the skills of experienced AH practitioners and to subsequently unload medical practitioners of routine activities. ${ }^{29,30}$ Extension of scope for $\mathrm{AH}$ practitioners may or may not be supported by formal training, credentialing, and legislation.

\section{Why do patients/customers seek AH care?}

Classifying why patients/customers seek AH treatment is an important quality measure. If assessment or diagnostic services only are provided, this is often to inform future care provision by the same $\mathrm{AH}$ discipline, other $\mathrm{AH}$ disciplines, and/or medical disciplines. When symptoms (such as pain and functional constraints) are reasons for individuals seeking $\mathrm{AH}$ care, then this usually attracts therapy, counseling, and/or educational aspects to manage.

\section{Measures of AH care outcomes}

AH disciplines and $\mathrm{AH}$ services are not homogenous. ${ }^{2}$ Therefore there is unlikely to be a "one-size-fits-all" approach, where one outcome provides a sensitive and reliable measure of $\mathrm{AH}$ service quality. Outcomes should be relevant to $\mathrm{AH}$ tasks, customers, reasons for service delivery, and the environment in which services are provided. Outcomes may reflect compliance with agreed processes (such as clinical guidelines or protocols), participation in multidisciplinary teams, and/or care outcomes (health or cost measures). There are no agreed standard psychometricallysound outcome measures collected by AH practitioners for any task they undertake. The most basic outcome measures are usually those dictated by the mandate of their employer for cost accounting or throughput measurement purposes. Even if there is agreement of what outcome measures to collect, issues such as how to interpret outcome measure scores, the most accurate and efficient mechanisms to collect data, and appropriate data analysis approaches present a challenge. For outcome measures to be useful, they need to be valid, collected accurately, and regularly shared with others. This requires significant information technology (IT) supports, as well as standard frameworks for understanding psychometric properties, data analysis, and reporting.

Where AH care relates only to assessment and/or diagnosis (such as provided by an audiologist or laboratory technician) an appropriate measure of care may be the sensitive and specific choice and application of diagnostic and assessment tools, followed by the timely arrival at a likely diagnosis and/or identification of risk factors pertinent to future treatment plans. Other measures may be the timeliness of the reporting of diagnostic findings to other health providers, choice of the correct measure of assessment/diagnosis, or error/failure rates.

Where AH disciplines provide treatment (therapy, counseling, education) (grouped as "therapy" in this paper), measures of care usually relate to the nature of the service (what is done, by whom, how often, etc) and/or the outcome of care. There remains the unanswered question of how best to demonstrate effectiveness of AH treatment; should this be addressed by throughput measures such as waiting times and numbers of treatments provided, or should it be assessed as patient satisfaction, or arrival at an agreed health outcome or goal, or should it relate to application of clinical guidelines? There have been concerted attempts in Australia to describe why AH services are provided and a standard has been developed after lengthy consultation within and between AH professions on how best to describe their activities. ${ }^{31}$ However, this standard is not in wide use.

Considering the range of health outcomes that could be used to measure $\mathrm{AH}$ effectiveness, there is a general focus on function, which is currently measured by the World Health Organization in terms of impairment, ability and participation. ${ }^{32}$ It is logical to measure impairment using objective measures (such as range of movement, strength, capacity to undertake a specific task, etc). While pain is also classified as impairment, this is much more difficult to measure because of its subjective characteristics, individual nature, and complex presentations which can involve multiple body systems, particularly when pain becomes chronic. ${ }^{33}$ It is challenging to capture valid and accurate information about function because of the plethora of outcome measures from which to choose, the variable evidence of psychometric properties for these measures, and lack of agreement about the key features of function relevant to different types of patients in different circumstances. Thus for $\mathrm{AH}$ "therapists" this means that demonstrations of the effectiveness of their care using measures of ability or participation may be constrained by the very nature of measures that are valued by other customers/stakeholders. It also means that when there is no longer any benefit of further therapy, it may be difficult for some therapists and patients to establish common ground on how to proceed.

\section{Who pays and for what?}

There is almost no research evidence underpinning any $\mathrm{AH}$ purchasing or quality monitoring strategy around the world, 
in terms of capturing the costs and quality of AH processes or outcomes. "Fragmented" appears to be the best descriptor of AH service provision and funding arrangements in many countries. In Australia, AH services can be provided in the private sector (private hospitals or clinics), where patients may pay outright for the service, or the patient may be variably reimbursed under compensable arrangements. When the patient pays privately for the cost of their $\mathrm{AH}$ treatment and it is not related to a compensable work or road injury, or military service, reimbursement may be sought by the individual from their private health fund. The reimbursement depends on the level of "private health coverage" which had been purchased by the patient, and the requirements of, and/or limitations set by, the insurer. Where a compensable body is involved in payment for private sector $\mathrm{AH}$ care, management of claims, limits on reimbursements, legislative constraints on service delivery and payment, and fund holder responsibilities differ between schemes. This is a particular issue in Australia with different compensation schemes operating in the different states, using differently worded legislation.

In the Australian public sector, patients can receive $\mathrm{AH}$ services "free of charge" via the public Medicare funding system to which wage earners contribute by general levy. Patients may receive AH services as part of an acute hospital admission, and they may also attend public hospital outpatient clinics or community health centres for $\mathrm{AH}$ care with or without a related hospital admission. There is often a waiting list for outpatient public AH services. Some public organizations require a co-contribution from patients to defray costs and encourage attendance.

\section{Measures of AH service delivery}

There are several models of AH service delivery. AH practitioners who primarily diagnose or assess may have only one or two contacts with patients (counted as occasions of service). Other AH practitioners who treat, counsel, educate, and/or manufacture ("therapy") may have more contact over longer time periods (episodes of care).

"Occasions of service" is the term which refers to individual (non-linked) contacts between a patient and a healthcare provider, while an "episode of care" reflects linked and cumulative occasions of service for the management of one condition. Occasions of service are a commonly used international measure of most health service delivery (medical, nursing, AH), while episodes of care are less commonly considered. The terminology would appear to be linked to the model under which care is provided (described later in this paper as medical or biopsychosocial). Many private or compensable insurers place a limit on the number of AH occasions of service which will be refunded for one patient within one time period (per year or per claim), without factoring in reasons for seeking treatment (for instance complicated, complex conditions versus simple conditions). This potentially leads to under- or over-use of AH services.

$\mathrm{AH}$ "therapists" generally provide linked occasions of service for one patient, for the management of one presenting condition. We previously defined an episode of care as: "[Theoretically] comprising all those occasions of service provided to the one patient for the one condition in the one allied health outpatient service, using the one referral." 34

An episode of care can take several forms. It can consist of only one occasion of service, or multiple linked occasions of services (in which treatment can stop and start over time). There is a lack of clarity about the nature of what happens in linked occasions of service (ie, an episode of care), particularly considering the expectations and decisions made by patients and $\mathrm{AH}$ therapists individually or together. This is underpinned by a lack of understanding about $\mathrm{AH}$ therapist-patient relationships, the nature of $\mathrm{AH}$ services provided throughout an episode of care, change in outcome measures, and why patients choose to cease (or continue) treatment.

Within episodes of care for particular conditions managed by $\mathrm{AH}$ therapies, there is almost no research on the rate of change in outcome measures throughout the episode, or how much treatment is required to produce a valued outcome. There are only a few comparative papers ${ }^{35-38}$ that consider the outcomes and costs of different physiotherapy service consumption models. These papers found similar health outcomes comparing shorter with longer service consumption models and found significantly greater costs and patient dependency associated with the latter. This suggests that longer episodes of consumption of allied health care may be more related to market forces than patient health need. ${ }^{38}$

Currently there are minimal opportunities at any service delivery monitoring level to link diagnosis (or reason for seeking care) and occasions of service/episodes of AH care. Thus AH service consumption or service quality is rarely evaluated in terms of diagnosis, clinical need, evidencebased practice, or prognosis. Anecdotally, this results in practitioners who treat patients with high, complex, and ongoing needs (brain injury, multiple musculoskeletal trauma, chronic pathologies) in being regularly questioned 
by third party insurers (ie, insurer investigators), regarding their unusually high service delivery profiles. It also reflects the lack of realistic service provision profiles for common conditions against which to benchmark what is reasonable and what should be investigated.

"Maintenance therapy" is treatment provided to an individual whose health condition is unlikely to improve (for instance, irreversible changes to tissue resultant from injury/ageing/pathology) and whose health condition may deteriorate if appropriate treatment is not provided. There have been a small number of scholarly papers arguing the validity of this treatment approach, although this has generally not been translated into policy. ${ }^{39-41}$ As a consequence, there is a lack of clarity amongst $\mathrm{AH}$ practitioners about the most effective management approach when faced with this situation. Regular small amounts of AH care may well provide patients with chronic conditions with the motivation to monitor their own health, and actively commit to optimising it by self-management strategies. However, regular $\mathrm{AH}$ care may provide patients with negative messages regarding condition ownership and self-management (an "opt out" of doing anything to help themselves). The use and benefits of maintenance therapy appears to rest with the contract/goal setting made between the $\mathrm{AH}$ practitioner and patient. ${ }^{39}$

The essence of maintenance therapy is to maintain the status quo (preventing the condition from getting worse). ${ }^{40}$ To justify maintenance treatment, the regular use of functional goal-driven outcome measures is required, with regular withdrawal of care for periods of time, to test whether, without it, patients deteriorate in important outcomes. This is a situation where the use of appropriately sensitive patient-specific outcomes are highlighted, as acute condition outcome measures may not be sufficiently sensitive to detect important outcomes in chronic conditions.

\section{Models of AH care}

The literature describes two main models underpinning AH care:

- The historical medical/biomedical model of care, in which the care is symptom- or disease-focused, and a medical practitioner usually acts as the "gatekeeper" of service delivery. ${ }^{42} \mathrm{AH}$ care is often regulated by prescribed numbers of treatment, or treatment periods.

- The biopsychosocial model of care, in which a holistic focus is taken of patients' needs, recognising biological, psychological, and social elements as integral to determining the most appropriate $\mathrm{AH}$ care and how it is delivered..$^{43}$
Most health systems around the world primarily work under the medical model of health care in the context of $\mathrm{AH}$ service provision. This reflects the historical arrangement of AH services, based on licensed and hierarchical expertise of healthcare providers, where doctors are generally the primary decision-makers. It has been described as an authoritarian and "paternalistic" approach, and traditionally focused on intervention, where the patient is the passive recipient of care. This approach fits the historical disease model, which was systems-focused, and did not incorporate elements of psychological, emotional, or social health. Thus, under this model, disease is managed biomedically, with no overt recognition of the social, psychological, and behavioral dimensions of illness. ${ }^{44,45}$

The biopsychosocial model is more recent, based on emergent public health research about the interactions of an injured or ill individual operating within their experience, their culture, and their social and physical environments. ${ }^{46}$ The concept of AH service provision under this model has been led by educators and researchers in Australia and the UK. ${ }^{33,47,48}$ While there has been sound ground work in educating $\mathrm{AH}$ practitioners about applying this model in practice, and encouraging relevant collection of patient and service-delivery data, there has been very little work in operationalizing this model in terms of $\mathrm{AH}$ service quality measures. Areas which require attention under this model are developing recognized and funded referral pathways, provider networks, IT support systems to assist in data collection and analysis, and obtaining overt support from insurers for general health care provider education to put this new way of thinking into place.

\section{Evidence-based practice}

Evidence-based practice is an element of quality AH care, the other elements being clinician judgement, patient preference and context/environment. ${ }^{49}$ However, operationalizing the integration of evidence into clinical $\mathrm{AH}$ practice and quality monitoring is in its infancy. The literature abounds with debate about what constitutes "evidence," with tensions between clinician experience and/or clinical reasoning as the most appropriate ways of determining treatment plans, compared with sole reliance on research evidence (where unless the evidence comes from a randomized controlled trial or systematic review, there is "no evidence"). It is well documented that many $\mathrm{AH}$ practitioners have difficulty accessing up-to-date research evidence if they are not linked to a university or hospital library, and/or do not have the requisite skills to find the material. There is also the potential 
for poor quality evidence to be applied if practitioners do not have the time or skills to critically appraise the research literature. ${ }^{49,50}$

Clinical guidelines and treatment protocols have been developed and promoted internationally to underpin evidencebased AH management of many conditions. Well-constructed guidelines which follow a documented and agreed process aim to provide believable syntheses of current research evidence. ${ }^{51}$ This supports operationalization of evidencebased practice by "average" practitioners for "average" patients using clinical reasoning relevant to discipline training, patient preference, and local environments. High quality guidelines are regularly produced by credible agencies such as the SIGN, ${ }^{52} \mathrm{NICE},{ }^{53} \mathrm{NHMRC},{ }^{54}$ and NZGG. ${ }^{55}$ These guidelines offer a ready way for $\mathrm{AH}$ practitioners to access carefully evaluated and synthesized information on best practice care. ${ }^{51}$

Under the medical model, evidence ranges from acceptable clinical opinion through to scientifically rigorous published evidence. Where scientific published evidence is available, it is generally empirical. There are well recognized limitations on empirical research evidence with respect to clinical uptake. While randomized controlled trials (RCTs) are considered to be the gold standard research to inform treatment decisions, few RCTs in AH have been designed to mirror "usual clinical practice." 56 Thus, they usually specify a number of treatments, a defined patient group and intervention, and rarely incorporate clinician judgement, patients with high risks of poor outcome, patient-clinician goals, or speed of resolution of an individual's presenting symptoms. Such studies generally dictate inclusion/exclusion criteria that may limit applicability to the "usual" patient, and/or exclude "unusual patients" from the research. The lack of incorporation of research evidence into clinical practice has underpinned the development of the $\mathrm{EPOC}^{57}$ which aims to assist in the translation of evidence into practice by conducting practice-focused systematic literature reviews.

While there is a considerable volume of supportive texts and conference presentations for the biopsychosocial model, there is a scant scientific evidence base. There was an inconclusive systematic literature review regarding the benefits of the biopsychosocial model of care in physiotherapy, ${ }^{58}$ a more supportive review in the same year about client belief systems, ${ }^{59}$ and a recent review which reports some evidence of benefit, albeit from a small number of included studies. ${ }^{60}$ In the last 5 years, several RCTs have been published which tested a biopsychosocial approach to care delivery in therapy-related areas, consistently identifying that early active intervention including patient education and self-management instruction coupled with AH treatment significantly improved health and emotional outcomes. ${ }^{61-63}$ Operationalizing the biopsychosocial model in wide practice is in its infancy however, with Astin et $\mathrm{al}^{64}$ highlighting the minimal impact that the biopsychosocial model of healthcare has on medical students' and residents' thinking. This suggests that despite an increasing evidence base for its appropriateness for $\mathrm{AH}$ management, multidisciplinary networks which are based on this way of thinking may be slower to develop.

\section{Risk factors for poor health and costs outcomes}

Risk factors which may adversely influence an individual's capacity to respond to AH care can include personal, demographic, social, emotional, and occupational factors. These are sometimes described as "flags." 65 There is no standard process for assessing risk factors, little consideration of the relevance of risk factors to AH care decisions, and no standard way of capturing them or investigating their impact on health outcomes.

The biopsychosocial model has spawned the recognition of the importance of assessing a range of aspects of a patient's presentation other than history and presenting symptoms. Clinical red flags are routinely used to assess musculoskeletal conditions (most commonly low back pain) under both the biomedical and biopsychosocial models, to identify the presence of pathologies which may preclude conservative treatment, or which require further investigation before appropriate treatment can commence. Assessment of other risks for poor outcomes (using clinical yellow, blue, and black flags) has also been promoted. ${ }^{65-67}$ Yellow flags are psychosocial barriers to recovery, blue flags relate to conditions in the workplace which may constrain recovery, and black flags relate to organizational and compensation issues. The identification of non-red flags has been variably adopted in Australian healthcare practice, largely because of concerns about diagnostic accuracy of the available instruments. ${ }^{68-70}$ A practical guideline to assessing low back pain was produced for Australian doctors ${ }^{71}$ incorporating only red and yellow flags.

There is also scant high level research evidence detailing how individual risk factors influence individuals' responses to treatment. The reason for the lack of research evidence is the difficulty in quantifying risks, and their impact on the outcome of care. For instance, some risks may be present when a patient first presents to an $\mathrm{AH}$ practitioner, and therefore should be identifiable with appropriate initial history taking and screening. Other risks for poor outcome may develop 
over time, relative to circumstance, environment, personal relationships, expectations, and/or response to treatment. Some risks may be latent, and may emerge during the episode of care because of the relationship which develops between the $\mathrm{AH}$ practitioner, the patient, and family. There is an urgent need for more research into assessment and classification of risk factors, their presence/absence at specific time points throughout an episode of care, their influence on outcomes, and AH practitioners' capacity to identify and deal with risk factors in terms of timely assessment and monitoring, treatment and/or referral to other health practitioners.

There is a lack of standard IT/record-keeping approaches to storing and retrieving information on health outcomes and risk factors. AH practitioners could realistically collect this information on hard copy and attach it to a patient's file, however without purpose-built software, it would be difficult to retrieve or collate this information. At present, therefore, it is a potentially time-consuming task to calculate the scores from any instrument promoted to assess flags, and to determine whether a patient is at risk of poor outcomes.

There are few agreed practices regarding referral of at risk patients to appropriate specialists for the management of identified psychosocial or environmental concerns, and no specific clinical guidelines for the management of patients deemed to be "at risk." Thus it could realistically happen that an $\mathrm{AH}$ practitioner may appropriately identify a patient as at risk of a poor outcome because of high risk scores, and then have no agreed pathway to ensure ongoing best practice management for this patient.

\section{Information provided by $\mathbf{A H}$ practitioners to support evaluation of quality}

There is no international standard for collecting information on, or monitoring of, the quality of AH care.

In many public health care institutions, health care quality is measured by default as a percentage of direct patient contact and indirect contact time. This is usually measured routinely, however research into how healthcare providers spend their time is scant, and there is no recent information in Australia on AH activities. ${ }^{72}$ There are also poorly described differences between $\mathrm{AH}$ disciplines regarding the variability of time spent on direct and indirect contact, reflecting discipline-specific core business and tasks. Thus benchmarks of expected performance or ideal ratios between direct and indirect time have yet to be developed.

In many instances, only basic information is recorded by $\mathrm{AH}$ practitioners regarding patient and service descriptors (identifier, age, sex, compensable status, and dates of treatment). In some instances, basic diagnostic information (such as body part being treated) may be recorded, although information on patient outcome is rarely provided. There is no standard way of describing conditions treated by $\mathrm{AH}$ or measuring outcomes and if $\mathrm{AH}$ data collection systems are "stand alone" (not linked with a hospital data collection system) there is no opportunity to link $\mathrm{AH}$ activities for specific patients with other healthcare activities or outcomes. Therefore costs and activities required to obtain desirable $\mathrm{AH}$ outcomes remain poorly understood.

\section{IT support systems}

There are a plethora of purpose-built organization-specific IT systems which collect and analyze fragmented pieces of information about health service quality. ${ }^{73}$ Most IT systems are historical and appear to have evolved over time to meet organizational requirements with minimal forward planning. ${ }^{74}$ In our experience, most are unwieldy to manage (including their capacity to assist in compiling timely and relevant reports), and many did not incorporate crucial information such as the condition for which treatment was provided, or markers of episode commencement and closure, or processes and outcomes of care. ${ }^{75}$ It is common for multiple handling of patient data to occur, raising the potential for errors. Due to lack of flexibility of many IT systems, there is often limited capacity for updating and rectifying errors in data entry. In instances where codes have been used for data entry, these codes are generally selected by the healthcare provider who first assessed the patient, thereby documenting early information (perhaps a provisional diagnosis). This is subsequently rarely amended to reflect changing health conditions, or the emergence of flags which may signal changes to the patients' potential for improvement. Therefore lack of robust AH data and IT support systems means a general inability to accurately capture, measure, and reflect on AH service delivery. ${ }^{75}$

\section{Conclusion}

This evidence-informed analytical review outlines many factors which should be considered by AH leaders in policy and service delivery regarding informed choices of sensitive and reliable measures of AH service quality. Strong, visionary, and collaborative leadership is required to ensure that $\mathrm{AH}$ activities and outcomes are measured and reported appropriately in order to demonstrate the impact of $\mathrm{AH}$ within a service.

While there is increasing recognition worldwide of the need for quality measures to inform and underpin AH service 
delivery, there is scant research, policy, or clinical evidence regarding real-world operationalization. This appears to be, in part, due to the diversity of health disciplines which fall under the AH umbrella, the variety of roles and tasks these disciplines undertake, and lack of standard data items, data collection processes, and dedicated support systems to capture the range of services that $\mathrm{AH}$ provides. It is clear therefore, that there is "no one size fits all" measure of AH quality. AH quality measures should be multidimensional to reflect the complexity of service delivery approaches and tasks.

This evidence-informed critical literature review was undertaken with the aim of stimulating discussion on the multiple factors which should be considered when developing sensitive, comprehensive and reliable measures of $\mathrm{AH}$ service quality. Figure 1 highlights the intricacies of these factors, and how one measurement of one factor may impact on measurement of others. Discussion must consider the potential burden of data collection on busy AH staff. Regular recording of activities for quality monitoring may reduce the direct contact activity time that is the core business of AH disciplines. Thus any data collection needs to focus on the minimum number of defensible core items that describe AH quality as a collective, as well as core items relevant to specific AH disciplines. Such data collection needs to be finely balanced in order to minimize impact on core business, while ensuring that $\mathrm{AH}$ quality becomes readily measureable and reportable.

\section{Disclosure}

The authors report no conflicts of interest in this work.

\section{References}

1. Berwick DM. Toward an applied technology for quality measurement in health. Med Decis Making. 1988;8(4):253-258.

2. Turnbull C, Grimmer-Somers K, Kumar S, May E, Law D, Ashworth E. Allied, scientific and complementary health professionals: a new model for Australian allied health. Aust Health Rev. 2009;33(1):27-37.

3. Fitzgerald K, Hudson L, Hornsby D. A Study of Allied Health Professionals in Rural and Remote Australia. Canberra, Australia: Services for Australian Rural and Remote Allied Health, Incorporated; 2000:1-112

4. sarrah.org.au [webpage on the Internet]. Australia: Clinical Allied Health Professions - A Method of Classification Developed from Common Usage of the Term 'allied health' - As Applicable to Rural and Remote Australia. 2001. Available from: http://www.sarrah.org.au/site/index. $\mathrm{cfm}$ ?display=65820. Accessed April 19, 2012.

5. ahwo.gov.au [homepage on the Internet]. The Australian Allied Health Workforce: An Overview of Workforce Planning Issues. AHWAC Report 2006.1. North Sydney: Australian Health Workforce Advisory Committee; 2006. Available from: http://www.ahwo.gov. au/documents/Publications/2006/The\%20Australian\%20allied\%20 health\%20workforce.pdf. Accessed April 19, 2012.

6. asahp.org [homepage on the Internet]. Allied health professionals. Washington, DC: The Association of Schools of Allied Health Professionals; 2011. Available from: http://www.asahp.org/definition. htm. Accessed April 27, 2012.
7. health.qld.gov.au [homepage on the Internet]. Allied heath career structure. Queensland Government; 2010 [updated October 28, 2011]. Available from: http://www.health.qld.gov.au/allied/career-structure. asp. Accessed April 27, 2010.

8. nhscareers.nhs.uk [homepage on the Internet]. UK: Allied health professionals: key players in the healthcare team. NHS Careers; 2006. Available from: http://www.nhscareers.nhs.uk/ahp.shtml. Accessed April 27, 2010.

9. World Health Organization. Allied health (paramedical) services and education. Report of an intercountry consultation. Bangkok, Thailand. WHO Regional Office for South-East Asia, New Delhi; March 20-24, 2000.

10. Struber J. Recruiting and retaining allied health professionals in rural Australia: why is it so difficult? The Internet Journal of Allied Health Sciences and Practice [serial on the Internet]. Apr 2004:2(2). Available from: http://ijahsp.nova.edu/articles/Vol2num2/struber_rural.htm. Accessed June 13, 2012.

11. aihw.gov.au [homepage on the Internet]. Health workforce. Australian Institute of Health and Welfare; 2011. Available from: http://www. aihw.gov.au/health-workforce/. Accessed April 20, 2011.

12. Arah, OA, Westert GP, Hurst J, Klazinga NS. A conceptual framework for the OECD Health Care Quality Indicators Project. Int J Qual Health Care. 2006;18 Supp1 1:5-13.

13. Grimmer K, Sheppard L, Pitt M, Magarey M, Trott P. Differences in stakeholder expectations in the outcome of physiotherapy management of acute low back pain. Int J Qual Health Care. 1999;11(2):155-156.

14. Bialocerkowski AE, Grimmer KA, Milanese SF, Kumar VS. Applicability of current research evidence to clinical physiotherapy practice. J Allied Health. 2004;33(4):230-237.

15. Bickenbach JE, Chatterji S, Badley EM, Ustün TB. Models of disablement, universalism and the international classification of impairments, disabilities and handicaps. Soc Sci Med. 1999;48(9):1173-1187.

16. abs.gov.au [homepage on the Internet]. Allied health industries survey. Australian Bureau of Statistics [updated September 14, 2011]. Available from: http://www.abs.gov.au/AUSSTATS/abs@.nsf/DOSSbytitle/05 6B91D1D1EF8264CA256BD00027E161?OpenDocument. Accessed April 17, 2012.

17. Grimmer K, Kumar S. Allied health task-related evidence. Journal of Social Work Research and Evaluation. 2005;6(2):143-154.

18. Schoop M. An empirical study of multidisciplinary communication in healthcare using a language-action perspective. In: Goldkuhl G, Lind M, Seigerroth U, editors. Proceedings of the 4th International Workshop on the Language Action Perspective on Communication Modelling; Copenhagen, Denmark. September, 12-13 1999; 1999:59-72.

19. Worley P, Martin A, Prideaux D, Woodman R, Worley E, Lowe M. Vocational career paths of graduate entry medical students at Flinders University: a comparison of rural, remote and tertiary tracks. Med $J$ Aust. 2008;188(3):177-178.

20. Schuster ND, Nelson DL, Quisling C. Burnout among physical therapists. Phys Ther. 1984;64(3):299-303.

21. Campo MA, Weiser S, Koenig KL. Job strain in physical therapists. Phys Ther. 2009;89(9):946-956.

22. Balogun JA, Titiloye V, Balogun A, Oyeyemi A, Katz J. Prevalence and determinants of burnout among physical and occupational therapists. J Allied Health. 2002;31(3):131-139.

23. Gadiel D, Ridoutt L. Towards a rural allied health strategy: A workforce and economic analysis of allied health in New South Wales. Aust $J$ Rural Health. 1994;2(3):29-32.

24. Bowman, P. Director General's Allied Health Recruitment and Retention Taskforce: Summary Report, July 1999-March 2000. Queensland Health Scientific Services: Brisbane; 2001.

25. O'Kane A, Curry R. Unveiling the secrets of the allied health workforce. Symposium paper. Proceedings of the 7th National Rural Health Conference; Hobart: March 1-4, 2003.

26. Paskevicius A. Western Australian Allied Health Taskforce on Workplace Issues. Initial Report 2002. Perth: Health Department of Western Australia; 2002. 
27. Gilmore L, Morris J, Murphy K, Grimmer-Somers K, Kumar S. Skills escalator in allied health: a time for reflection and refocus. Journal of Healthcare Leadership. 2011;3:53-58.

28. Duckett SJ. Health workforce design for the 21 st century. Aust Health Rev. 2005;29(2):201-210.

29. Morris J, Grimmer-Somers K, Kumar S, et al. Effectiveness of a physiotherapy-initiated telephone triage of orthopaedic waitlist patients. Patient Relat Outcome Meas. 2011;2:151-159.

30. Ruston SA. Extended scope practitioners and clinical specialists: a place in rural health? Aust J Rural Health. 2008;16(3):120-123.

31. nahcc.org.au [homepage on the Internet]. IFI Coding Manual. National Allied Health Classification Committee (NAHCC); 2007. Available from http://www.nahcc.org.au/Microsoft\%20Word\%20-\%20Appendix $\% 20$ E\%20-\%20IFI\%20FInal\%20Report\%20-\%20\%20IFI\%20Coding\%20 Manual\%20pp85-159.pdf. Accessed April 16, 2012.

32. who.int [homepage on the Internet]. International classification of functioning, disability and health (ICF). World Health Organization; 2012. Available from http://www.who.int/classifications/icf/en/. Accessed April 20, 2011.

33. Butler D, Moseley L. Explain Pain. Noigroup Publications; 2004.

34. Grimmer K, Bowman P, Roper J. Episodes of allied health outpatient care: an investigation of service delivery in acute public hospital settings. Disabil Rehabil. 2000;22(1-2):80-87.

35. Hendriks EJ, Kerssens JJ, Nelson RM, Oostendorp RA, van der Zee J. One-time physical therapist consultation in primary health care. Phys Ther. 2003;83(10):918-931.

36. Hendriks HJM, Kerssens JJ, Heerkens YF, et al. Referral patterns and utilization of physiotherapy services following a one-time physiotherapist consultation in general practice. Physiother Theory Pract. 2003;19(1):5-21.

37. Grimmer-Somers K, Milanese S, Brennan C, Mifsud I. Who uses physiotherapy services for motor vehicle-induced whiplash-associated disorders? interrogating motor accident insurance data for 2006-2009. Asia-Pacific Journal of Risk and Insurance (APJRI). 2011:5(1).

38. Grimmer-Somers K, Milanese S, Kumar S, Brennan C, Mifsud I. The number and frequency of physiotherapy services for motor vehicle-induced whiplash: Interrogating motor accident insurance data 2006-2009. J Rehab Med. 2012; In press.

39. Flanagan T, Coburn P, Harcourt P, Zylinski M, Jull G. Justifying the on-going physiotherapy management of long-term patients. Man Ther. 2003;8(4):254-256.

40. Flanagan T, Green S. The concept of maintenance physiotherapy. Aust J Physiother. 2000;46(4):271-278.

41. Norris P. How 'we' are different from 'them': occupational boundary maintenance in the treatment of musculo-skeletal problems. Sociol Health Illn. 2001;23(1):24-43.

42. Campbell SM, Roland MO, Buetow SA. Defining quality of care. Soc Sci Med. 2000;51(11):1611-1625.

43. Suls J, Rothman A. Evolution of the Biopsychosocial Model: Prospects and Challenges for Health Psychology. Health Psychology. 2004;23(2): $119-125$.

44. McCullough LB. Tracking the variability of authority and power in the physician-patient relationship. J Med Philos. 2009;34:1-5.

45. Engel GL. The clinical application of the biopsychosocial model. Am J Psychiatry. 1980;137(5):535-544.

46. Borrell-Carrió F, Suchman AL, Epstein RM. The biopsychosocial model 25 years later: principles, practice, and scientific inquiry. Ann Fam Med. 2004;2(6):576-582.

47. Gifford LS, Butler DS. The integration of pain sciences into clinical practice. J Hand Ther. 1997;10(2):86-95.

48. Jones M, Edwards I, Gifford L.Conceptual models for implementing biopsychosocial theory in clinical practice. Man Ther. 2002;7(1):2-9.

49. Hoffman T, Bennett S, Del Mar C. Evidence Based Practice: Across the Health Professions. Chatswood: Churchill Livingstone; 2009.

50. Grimmer-Somers K, Lekkas P, Nyland L, Young A, Kumar S. Perspectives on research evidence and clinical practice: a survey of Australian physiotherapists. Physiother Res Int. 2007;12(3):147-161.
51. Holohan V, Deenadayalan Y, Grimmer K. Evidence-based physiotherapy for acute low back pain: Development of a composite clinical algorithm synthesised from seven recent clinical guidelines. Physiotherapy Canada. 2006;58:280-290.

52. sign.ac.uk [homepage on the Internet]. Sign 127 Management of perinatal mood disorders. Edinburgh: Scottish Intercollegiate Guidelines Network (SIGN); 2001-2012 [updated June 12, 2012]. Available from http://www.sign.ac.uk/. Accessed April 17, 2012.

53. nice.org.uk [homepage on the Internet]. UK: National Institute for Clinical Excellence (NICE). Available from: http://www.nice.org.uk. Accessed April 17, 2012.

54. nhmrc.gov.au [homepage on the Internet]. Australia: National Health and Medical Research Council (NHMRC). Available from: http://www. nhmrc.gov.au. Accessed April 17, 2012.

55. nzgg.org.nz [homepage on the Internet]. New Zealand: New Zealand Guidelines Group (NZGG). Available from: http://www.nzgg.org.nz. Accessed April 17, 2012.

56. Milanese S. The use of RCT's in manual therapy - are we trying to fit a round peg into a square hole? Man Ther. 2011;16(4):403-405.

57. epoc.cochrane.org [homepage on the Internet]. Ottawa, ON: Cochrane Effective Practice and Organization of Care Group. Available from: http://www.epoc.cochrane.org. Accessed April 17, 2012.

58. Karjalainen K, Malmivaara A, van Tulder M, et al. Multidisciplinary biopsychosocial rehabilitation for neck and shoulder pain among working age adults: a systematic review within the framework of the Cochrane Collaboration Back Review Group. Spine (Phila Pa 1976). 2001;26(2):174-181.

59. Mondloch MV, Cole DV, Frank JW. Does how you do depend on how you think you'll do? A systematic review of the evidence for a relation between patients' recovery expectations and health outcomes. CMAJ. 2001;165(2):174-179.

60. George S. What is the effectiveness of a biopsychosocial approach to individual physiotherapy care for chronic low back pain? The Internet Journal of Allied Health Sciences and Practic [serial on the Internet]. Jan 2008:6(1). Available from: http://ijahsp.nova.edu/articles/ vol6num1/george.htm. Accessed June 13, 2012.

61. Wand BM, Bird C, McAuley JH, Doré CJ, MacDowell M, DeSouza LH. Early intervention for the management of acute low back pain: a single-blind randomized controlled trial of biopsychosocial education, manual therapy, and exercise. Spine (Phila Pa 1976). 2004; 29(21):2350-2356.

62. Mårtensson L, Marklund B, Baigi A, Gunnarsson M, Fridlund B. Long-term influences of a biopsychosocial rehabilitation programme for chronic pain patients. Musculoskeletal Care. 2004;2(3):152-164.

63. Schiltenwolf M, Buchner M, Heindl B, Jvon Reumont J, Müller A, Eich W. Comparison of a biopsychosocial therapy (BT) with a conventional biomedical therapy (MT) of subacute low back pain in the first episode of sick leave: a randomized controlled trial. Eur Spine J. 2006;15(7):1083-1092.

64. Astin JA, Sierpina VS, Forys K, Clarridge B. Integration of the biopsychosocial model: perspectives of medical students and residents. Acad Med. 2008;83(1):20-27.

65. Lambeek LC, van Mechelen W, Knol DL, Loisel P, Anema JR. Randomised controlled trial of integrated care to reduce disability from chronic low back pain in working and private life. BMJ. 2010; 340:c1035.

66. Main CJ, Williams A. Musculoskeletal pain. BMJ. 2002;325(7363): 534-537.

67. Linton SJ, Halldén K. Can we screen for problematic back pain? A screening questionnaire for predicting outcome in acute and subacute back pain. Clin J Pain. 1998;14(3):209-215.

68. Grimmer-Somers K, Prior M, Robertson J. Yellow flag scores in a compensable New Zealand cohort suffering acute low back pain. J Pain Res. 2008;1:15-25.

69. Hockings RL, McAuley JH, Maher CG. A systematic review of the predictive ability of the Orebro Musculoskeletal Pain Questionnaire. Spine (Phila Pa 1976). 2008;33(15):E494-E500. 
70. Westman A, Linton SJ, Ohrvik J, Wahlén P, Leppert J. Do psychosocial factors predict disability and health at a 3-year follow-up for patients with non-acute musculoskeletal pain? A validation of the Orebro Musculoskeletal Pain Screening Questionnaire. Eur J Pain. 2008;12(5):641-649.

71. Jensen S. Back pain-clinical assessment. Aust Fam Physician. 2004;33(6):397-401.

72. Westbrook JI, Ampt A, Kearney L, Rob MI. All in a day's work: an observational study to quantify how and with whom doctors on hospital wards spend their time. Med J Aust. 2008;188(9):506-509.
73. Chaudhry B, Wang J, Wu Y, et al. Systematic review: Impact of health information technology on quality, efficiency, and costs of medical care. Ann Intern Med. 2006;144(10):742-752.

74. Kelley, ET, Arispe I, Holmes J. Beyond the initial indicators: Lessons from the OECD Health Care Quality Indicators Project and the US National Healthcare Quality Report. Int J Qual Health Care. 2006;18(Suppl 1):45-51.

75. Kumar S, Grimmer K. You've collected data: what now? Proceedings from National SARRAH Conference; September 13-16, 2006; Albury, Australia.

\section{Publish your work in this journal}

The Journal of Healthcare Leadership is an international, peer-reviewed, open access journal focusing on leadership for the health profession. The journal is committed to the rapid publication of research focusing on but not limited to: Healthcare policy and law; Theoretical and practical aspects healthcare delivery; Interactions between healthcare and society and evidence-based practices;

\section{Dovepress}

Interdisciplinary decision-making; Philosophical and ethical issues; Hazard management; Research and opinion for health leadership; Leadership assessment. The manuscript management system is completely online and includes a very quick and fair peer-review system. Visit http://www.dovepress.com/ testimonials.php to read real quotes from published authors.

Submit your manuscript here: http://www.dovepress.com/journal-of-healthcare-leadership-journal 